\title{
A antropologia da natureza de Philippe Descola
}

Entrevista

Não restam quaisquer dúvidas quanto ao fato de Philippe Descola ser uma das grandes figuras da antropologia contemporânea. A posição que ocupa como titular da Cátedra de "Antropologia da natureza", que inaugurou em 2000, no Collège de France, a sua atuação na École des Hautes Études en Sciences Sociales e o reconhecimento da importância de sua obra, expresso em distinçôes institucionais, não dizem tudo sobre as grandes exigências que sustentam o seu trabalho: uma experiência etnográfica profunda, uma ambição teórica sólida e uma erudição sem par.

Se, por um lado, a sua obra escrita, no estilo elegante que é o seu, permite supor essas exigências, assim como reconhecer nelas o papel fundamental de Claude Lévi-Strauss em sua trajetória, por outro, a entrevista é uma ocasiáo privilegiada de tornar visíveis os seus efeitos no trabalho antropológico e, mais ainda, nas ciências sociais, hoje.

Foi assim que Descola, que esteve na Universidade Federal do Rio de Janeiro em 2012, como titular da Cátedra Claude Bernard, ${ }^{1}$ falou a um auditório de professores e alunos sobre a sua concepção de antropologia, sobre a sua experiência como curador da exposição La fabrique des images, em 2011, e sobre as suas perspectivas de estudo mais recentes, em torno de uma antropologia da paisagem. Ao final deste percurso em vários níveis, que vai da separação epistemológica entre ciências da natureza e ciências da cultura aos nossos próprios modos de percepção do mundo, praticamente tudo estará posto em questão e proposto a ser repensado, de modo a compor um notável sistema teórico que pretende, táo somente, ir além.

Andrea Daher: Como se pode ler em seu livro Par-delà nature et culture [Para além de natureza e cultura], ${ }^{2}$ seu projeto intelectual teve como ponto de partida uma humanização do mundo animal e vegetal pelos povos autóctones e desembocou numa espécie de extensão, de ampliaçáo da própria noção de natureza. Ela se torna uma espécie de continuum que integra os homens, os animais, as plantas, muito distante de nossas concepçôes mais comuns (por exemplo, a da natureza como exterioridade ou como espaço virgem). Aí se encontra

\footnotetext{
${ }^{1}$ Philippe Descola ocupou a Cátedra Claude Bernard a convite do Programa de Pós-graduação em História Social, do Programa de Pós-graduação em Sociologia e Antropologia e do Programa de Pós-graduaçáo em Antropologia Social, todos da UFRJ, em outubro de 2012. A tradução desta entrevista foi feita por Raquel Campos; a revisão, a edição final e a apresentação são de Andrea Daher.

2 DESCOLA, Philippe. Par-delà nature et culture. Paris: Gallimard, 2005.
}

Entrevista - DOI - http://dx.doi.org/10.1590/2237-101X014027013 
um deslocamento conceitual importante, nas definiçóes renovadas tanto de "antropologia" quanto de "natureza". Assim, se a proposição "antropologia da natureza", que intitula a sua Cátedra no Collège de France, é um oximoro, as duas concepçôes, uma vez renovadas, deixam de ser dois termos que se opóem. Dito isso, minha questão diz respeito justamente ao lugar de um projeto como o seu no âmbito das ciências humanas. Mais particularmente, perguntaria de que modo esse projeto abre as portas para uma relação entre as ciências humanas e as ciências da natureza, e mesmo as ciências cognitivas (que até pouco tempo não conheciam uma verdadeira legitimidade junto às ciências do social)?

Philippe Descola: Para responder à sua questão, acredito que seja necessário, em primeiro lugar, insistir num ponto particular - algo que aprendemos cedo em filosofia - e que é a distinção entre a economia da exposição e a economia da descoberta. No livro que você citou, Par-delà nature et culture, apresentei o que havia feito por meio de uma fórmula sintética de exposição que não refletia - ou muito mal, algo que só podia ser visto, talvez, em filigrana - a economia da descoberta. Ela se liga, é claro, à minha experiência de etnógrafo na Amazônia e às questôes que se colocaram para mim durante o trabalho de campo, a que foi impossível responder com as ferramentas intelectuais de que dispúnhamos na época. Eu tinha ido para a Amazônia estudar as relaçôes de uma sociedade com seu meio ambiente. Por quê? Em primeiro lugar, por uma razão muito simples, mas central: na reflexão que, há cinco séculos, fazem os europeus, as populaçôes das terras baixas da América do Sul são sucessivamente consideradas de maneira positiva, como em Montaigne, que via os índios como filósofos nus, vivendo dos frutos de uma natureza generosa, sem dificuldades; ou sob um aspecto negativo, tal como nos primeiros textos sobre a América, principalmente em Cristóvão Colombo: esses homens são canibais brutais, inteiramente determinados por sua natureza cruel e por seus instintos bestiais. Assim, essa questão da natureza é, desde a origem, consubstancial à reflexão europeia sobre os índios da América do Sul: é a natureza que os determina em seu ser, eles náo passam de um apêndice dela, tanto para o melhor, quanto para o pior. Quis desenvolver essa questáo por meio da etnografia, e me pareceu evidente que a Amazônia era o lugar ideal para tentar compreender essa situação. Na época em que comecei minha formação de etnólogo, no início dos anos 70, havia pouca coisa, na literatura etnográfica sobre a regiâo, que permitisse compreender a especificidade de suas sociedades. $\mathrm{O}$ socius amazônico era algo fuliginoso, sem substância e, no fundo, como Clastres havia sublinhado, continuávamos com a definição negativa que vinha desde o Renascimento: gente "sem fé, nem lei, nem rei". O desafio intelectual consistia, portanto, em evidenciar aquilo que se constituía como um tecido agregativo entre os índios da Amazônia, sem recair em perspectivas funcionalistas. E a relaçáo com a natureza me parecia uma boa porta de entrada para isso: era indiscutível que ela havia chamado a atenção desde os primeiros observadores, ainda que de modo enviesado. De fato, a literatura etnográfica disponível mostrava que os 
índios da Amazônia mantinham um tipo de relação social com as plantas e os animais que estendia o campo das relaçôes humanas a uma esfera muito mais ampla do que unicamente a dos seres humanos. Se, por um lado, os mecanismos que estávamos acostumados a encontrar quando fazíamos etnologia da África ou da Oceania eram inadequados para termos uma inteligibilidade dessas sociedades, por outro, a relaçâo singular que elas teciam com seus meios ambientes (que na época eu ainda chamava de "natural") as tornavam coletivos fora das normas. Assim, foi esse interesse que me levou até essa região do mundo. Na época, havia duas correntes dominantes na etnologia da Amazônia. Uma delas — que hoje desapareceu completamente, mas que ocupava muito espaço nas revistas científicas dos Estados Unidos - era o "materialismo ecológico" ou "materialismo cultural", cuja ambição era explicar as instituiçôes sociais em termos de adaptação funcional a fatores de limitação ambientais. Era uma forma de determinismo técnico e geográfico que retomava uma das duas figuras do índio da Amazônia, a figura negativa, na qual ele é inteiramente dominado pelos constrangimentos que o meio ambiente exerce sobre ele. A outra corrente - derivada em parte da obra de Lévi-Strauss, mas que havia sido levada adiante por alguns de seus discípulos - compreendia a natureza de maneira um tanto abstrata, como um grande léxico de propriedades no qual as sociedades vinham se abastecer para organizar essas propriedades em sistemas semânticos e simbólicos (os mitos, as classificaçóes etc.). Nos dois casos, o sistema concreto de interação com os não humanos não era levado em consideração. E parti para o trabalho de campo com a ideia de estudá-lo. Então, fiz o tipo de coisa que se faz no trabalho de campo - que não contarei em detalhes aqui - e que resultou na minha tese, publicada depois com o título La nature domestique [A natureza doméstica] ${ }^{3}$ Mas, no fundo, o que me impressionou, principalmente, nessa investigação etnográfica que conduzimos com Anne Christine Taylor foi essa relação contínua, constante, de interação pessoal entre os humanos e os não humanos através de todo tipo de dispositivos (como os encantamentos, ou seja, o discurso da alma que os humanos dirigem às almas das plantas e dos animais; ou os sonhos que mostravam como os não humanos, numa forma humana, vinham se dirigir aos humanos para lhes comunicar mensagens). Observei, assim, um mundo em que, muito além das relaçóes entre humanos, a relação com os seres da natureza desempenhava um papel central. O problema estava em saber como tratar essa relação com os não humanos. E, na época, a literatura antropológica era extremamente pusilânime sobre essa questáo. Na França, o efeito do que poderíamos chamar "racionalismo lévi-straussiano" - relacionado à desconfiança que Lévi-Strauss tinha em relaçáo ao rito e ao papel acessório que conferia à "mitologia implícita" - havia sido de minorar essas formas de interaçóes práticas entre humanos e não humanos, e havia poucas ferramentas intelectuais que permitissem conceituá-las. Pela minha formação filosófica, por ser Lévi-Strauss o orientador da minha tese e por eu estar, as-

\footnotetext{
${ }^{3}$ DESCOLA, Philippe. La nature domestique. Symbolisme et praxis dans l'écologie des Achuar. Paris: Maison des Sciences de l'Homme/Fondation Singer-Polignac, 1986.
} 
sim, imbuído de sua obra, uma delas já havia chamado minha atençấo. Embora inadequada para a Amazônia, ela podia ser transformada de modo a se tornar uma ferramenta pertinente: era a análise que Lévi-Strauss fazia do totemismo em Le totémisme aujourd'hui [O totemismo hoje]. ${ }^{4}$ Ele o define como um dispositivo classificatório que transpõe as distâncias diferenciais entre uma série natural - a descontinuidade morfológica entre as espécies para a esfera cultural - as distâncias diferenciais no interior da série dos grupos totêmicos. Em outras palavras, as descontinuidades naturais permitem conceituar as descontinuidades sociais. Evidentemente, no nosso caso, não se tratava, de modo algum, da mesma coisa, já que náo se havia observado, entre os Achuar, um dispositivo classificatório desse tipo, mas, antes, um sistema de interação de pessoa a pessoa no qual os humanos, as plantas e os animais eram todos tratados não de modo idêntico, é certo, mas em relativo pé de igualdade. Então, a minha primeira hipótese foi no sentido de pensar que, diferentemente do totemismo, o que ocorria no caso Achuar não era a utilização de categorias naturais para conceituar as categorias sociais, mas, sim, o inverso: a utilização de categorias oriundas da prática social para pensar a relação com os objetos naturais. E essas categorias entre os Achuar eram definidas pelas relaçôes de parentesco: a maternagem das plantas cultivadas pelas mulheres era uma relação de consanguinidade, enquanto a relaçáo dos homens com os animais caçados era uma relação de afinidade. Ora, num sistema de parentesco dravidiano como o dos Achuar, toda a esfera social é organizada em torno do contraste entre a consanguinidade e a afinidade: conforme se trate de um parente consanguíneo ou de um parente por aliança, as atitudes serão completamente diferentes. E esses dois grandes tipos de relação com outro humano eram então manipulados pelos Achuar para caracterizar as relaçôes diferenciadas com as plantas e os animais. A primeira interpretação que fiz consistia em dizer que, entre os Achuar, ao contrário do que ocorria no totemismo classificatório, eram as categorias elementares da prática social que serviam para pensar os tipos de interaçáo que podiam se desenvolver entre os humanos e os seres da natureza. Nos primeiros textos em que abordei essa questáo, no início dos anos 1990, decidi denominar isso "animismo", ressuscitando um termo consagrado pelo menos desde Tylor, mas que havia caído em certo descrédito. E, depois, as discussóes que tive ao longo do tempo — principalmente aqui, no Rio de Janeiro, com colegas, em particular com Viveiros de Castro, mas também com Bruno Latour, em Paris, ou Tim Ingold, no Reino Unido - me fizeram tomar consciência do fato de que esse contraste entre animismo e totemismo não era muito pertinente porque, ao utilizar o modelo do totemismo classificatório lévi-straussiano, eu havia importado o que havia por trás dele, a saber, uma separaçáo marcada entre natureza e sociedade, entre as descontinuidades da série natural e as da série cultural. Uma separação como tal náo tinha qualquer sentido nos coletivos animistas, no interior dos quais era arbitrário dizer que as categorias da prática social tinham uma antecedência lógica sobre as que regiam as relaçôes com os não humanos.

${ }^{4}$ LÉVI-STRAUSS, Claude. O totemismo hoje. Lisboa: Edições 70, 1986 [1962]. 
Então, ao longo do tempo, fabriquei esse modelo em etapas sucessivas, acrescentando-lhe peças e corretivos, de tal modo que, na sua forma se não definitiva, em todo caso a mais acabada (a que forneci em Par-delà nature et culture), tem-se a impressão de que se trata de um dispositivo hipotético dedutivo oriundo de uma operação antropológica clássica e não de uma generalização etnográfica por indução. Mas, na verdade, sem entrar no detalhe das etapas sucessivas que resultaram nesse modelo, é evidente que ele tem uma aparência um tanto artificial de completude que não revela nada sobre os arcabouços progressivos que a etnografia, a etnologia e a discussão com os colegas etnólogos permitiram construir.

Devo dizer, mais uma vez, que tenho uma formação filosófica, e uma das características da filosofia ocidental é a obsessão pelos fundamentos, de que é muito difícil se desvencilhar. Para fazer um parênteses, Lévi-Strauss havia feito sua tese de doutorado de Estado, Les structures élémentaires de la parenté [As estruturas elementares do parentesco], ${ }^{5}$ numa época em que era inconcebível não começar uma obra desse tipo por fundamentos filosóficos. Daí os desenvolvimentos iniciais sobre a passagem da natureza à cultura e a proibição do incesto como condição do intercâmbio matrimonial. Os filósofos se concentraram justamente nesses dois ou três primeiros capítulos para discutir Lévi-Strauss, pois se trata de um dos textos mais filosóficos que escreveu. Mas poderíamos suprimi-los completamente sem que isso mudasse em nada a natureza das demonstraçôes das estruturas elementares do parentesco. Assim, há sem dúvida esse efeito superficial de perfeição, de busca de uma simetria espelhada, que faz com que tenhamos tendência a eliminar as elaboraçôes que permitem a construção de um dispositivo desse tipo. Dito isso, de modo algum renego o caráter filosófico dessa elaboração inicial, uma vez que a ambição - e assim respondo à questão que você me fez — é reformar, transformar, de certo modo, os conceitos que as ciências sociais empregam para pensar os objetos que, durante muito tempo, foram caracterizados e problematizados por meio de ferramentas que havíamos forjado, nós mesmos, para pensar nossa trajetória histórica (quando digo "nós", para simplificar, refiro-me aos europeus a partir do século XVIII). Em todo caso, me parecia impossível continuar empregando ferramentas como "natureza", "cultura", "sociedade", "história" etc. para pensar realidades nas quais essas noçôes não faziam muito sentido. E para fazê-lo, era preciso, justamente, ir para além de, em direção a uma base mais profunda, de maneira a estabelecer novamente os fundamentos. Fundamentos diferentes dos que haviam sido utilizados anteriormente, talvez mais universais, o que no fundo faz do meu empreendimento uma teoria que se enraíza necessariamente no naturalismo (para empregar uma terminologia que me é cara, pois os fundamentos são verdadeiramente algo naturalista ou eurocêntrico, e devemos aos gregos a obsessão dos fundamentos). Mas eles me pareceram necessários para poder construir com mais segurança a minha análise a partir de um dispositivo simples. Por que um dispositivo simples? Porque há muito tempo sou partidário da navalha de Occam: as soluçôes filosóficas, lógicas ou matemáticas mais simples e elegantes

${ }^{5}$ LÉVI-STRAUSS, Claude. As estruturas elementares do parentesco. Petrópolis: Vozes, 1982 [1949]. 
são frequentemente as mais eficazes e produtivas. Daí o modelo que desenvolvi de um sujeito transcendental - mais uma vez, é uma ficçáo totalmente eurocêntrica, mas pouco importa - que vai detectar ou não continuidades ou descontinuidades entre si, como sujeito dotado de um aparelho de detecção, cognitivo, simples, e o que ele observa à sua volta. E isso ele pode fazer graças a duas ferramentas principais que denominei "interioridade" e "fisicalidade". A leitura que fiz de Husserl, muito cedo, me havia deixado essa ideia muito forte de que a experiência pré-predicativa se constrói a partir dessas duas ferramentas que são, para um sujeito que não conhece preliminarmente nada no mundo, sua intencionalidade e seu corpo. Trata-se, assim, de duas ferramentas que parecem constituir — de maneira bastante clara nos trabalhos que me interessam em psicologia cognitiva e, em particular, na psicologia do desenvolvimento - dois instrumentos importantes de conhecimento do mundo, inclusive para as crianças antes do estágio da linguagem. Esses instrumentos permitem detectar, entre os elementos de seu meio ambiente, de um lado, entidades às quais são atribuídos estados mentais (o que podemos chamar de "interioridade"); e, de outro, entidades de que se espera terem um determinado tipo de comportamento físico no mundo (a continuidade das trajetórias, a gravidade etc.).

Foi a economia da exposiçáo que me permitiu, em seguida, desenvolver esse modelo em Par-delà nature et culture. Mas entendo esse modelo inicial, no que diz respeito à relação entre filosofia e ciências sociais, de uma determinada maneira: é um pouco como uma máquina experimental que me permite captar um determinado tipo de fenômeno (é claro que este modelo não capta todos, evidentemente, mas apenas um determinado tipo de fenômeno). E isso me permite também organizar esses fenômenos segundo modelos de gênero particular, que permitem em seguida responder a questôes particulares. Portanto, é como um instrumento em física que capta os traços de determinados fenômenos e que permite, a partir desses traços, construir modelos para compreender as relaçôes de compatibilidade e de incompatibilidade entre eles. Eis o que me parece ser o mais interessante - na minha idade, acabei por saber mais ou menos o que me interessa em antropologia - e, talvez, esta seja uma das contribuiçôes mais importantes que a antropologia pode dar, pois ela nasceu, de certo modo, para responder a enigmas. Foi no último terço do século XIX que um grande dispositivo de triagem epistemológica se estabeleceu: uma época em que precisamente a distinção entre natureza e sociedade se consolidou através das discussões epistemológicas e filosóficas dos neokantianos, em particular na Alemanha, mas também através de estruturações institucionais, principalmente a separação entre as faculdades de ciências e de letras. E, nesse momento, chegam informaçôes fornecidas pelos primeiros etnógrafos, pelos administradores coloniais e pelos missionários, que dizem que, em certas partes do mundo, há populaçôes que não fazem distinção clara entre os humanos e os animais. Foi preciso, na época, resolver esse que era um escândalo lógico, e se atribuiu esta missão à antropologia. Em seguida, essa ideia se desenvolveu de tal maneira que a antropologia constituiu como campo a diversida- 
de máxima nas instituiçôes humanas. É verdade que a massa de informaçôes acumuladas pelos etnógrafos, combinada aos dados arqueológicos e históricos, faz com que o campo de jogo dos antropólogos seja constituído de uma quantidade imensa de instituiçóes, junto às quais se trata de compreender por que algumas informaçôes se combinam e outras não. Essas são as questôes que nos colocamos, nem sempre, aliás, de maneira sistemática, quando conversamos entre nós, antropólogos, com experiências etnográficas em regióes do mundo muito diferentes. Quando confrontamos nossas experiências, percebemos, no meio de uma conversa, que uma coisa que nos parece perfeitamente normal talvez seja considerada uma abominação um pouco mais adiante, e vice-versa. Essa é, pois, a ambição comparativa geral que motivou a minha reflexão.

Gostaria, agora, de retomar a questão da antropologia da natureza e do oximoro. No fundo, por que eu escolhi esse oximoro? Há muito tempo, quando fui contratado como maître de conférences na École des Hautes Études en Sciences Sociales, não havia a obrigação de dar aulas (era um período admirável). Era preciso escrever ao presidente dessa instituição para pedir autorizaçáo para oferecer um seminário. E como eu me interessava por aquelas questôes, escrevi a François Furet para lhe dizer que gostaria de oferecer um seminário que se chamaria "Problemas de antropologia da natureza". Ele me recebeu, entáo, e me disse: "Que título estranho!" Em matéria de antropologia, François Furet apreciava muito Pierre Clastres, e por isso tinha uma visão bastante sociocentrada, não somente da história europeia, mas também das sociedades náo europeias. Tivemos uma discussão bastante interessante, mas acho que ele não ficou, de modo algum, convencido da minha ambição de fazer entrar os não humanos no estudo da sociedade. Mas essa ideia de uma antropologia da natureza nasceu naquele momento como um oximoro, que me parece ser algo muito fecundo. Isso faz parte da herança marxista e hegeliana: uma contradição sempre faz as coisas avançarem. Mas não tenho, de modo algum, a ambição de fazer uma antropologia da natureza no sentido sistemático, ou seja, de me confinar naquilo que se chama habitualmente "antropologia ambiental". O que me interessa é desprovincianizar as ciências sociais, e isso de duas maneiras. De um lado, tentando contribuir para a produçáo de conceitos que sejam desistoricizados, ou seja, que não reflitam a gênese de nosso modo de problematizar, de maneira reflexiva, nossa própria trajetória histórica; e, de outro, como um modo de descobrir uma forma de acordo, de diálogo — não sei que termo empregar — com as ciências da natureza. Não se trata de um sonho de superar a distinção epistemológica (será preciso muito tempo antes que se veja qualquer mudança nesse âmbito), mas de encontrar um meio de mudar a natureza dos objetos aos quais nos dedicamos nas ciências sociais, de modo que sejam um pouco menos incompatíveis com os objetos tratados por algumas das ciências da natureza. Ora, para retomar a experiência de pensamento que evocava há pouco, o que esse sujeito transcendental detecta no mundo? Detecta processos, relaçôes, qualidades. Não há nada aí que seja específico das ciências sociais ou das ciências humanas. É verdade que, para 
retomar uma velha distinção filosófica, as ciências da natureza trabalham com as qualidades primeiras, e nós nos interessamos pela maneira como as pessoas fazem coisas originais com as qualidades segundas. Porém, mais uma vez, tanto faz: o que conta é a possibilidade de tornar, novamente, mais ou menos coextensivo o tipo de objeto pelo qual se interessam as ciências da natureza e as ciências da cultura. Este é um projeto que não é unicamente meu, e penso que o tipo de coisa que faço só é possível no interior de uma coletividade, de uma comunidade científica de pessoas que têm interesses intelectuais em comum, que debatem muito entre si, e numa situação histórica em que é evidente que a distinção entre natureza e sociedade deixou de ser pertinente. Estamos cercados todos os dias por manifestaçóes em que essa distinção se encontra abolida; e nós, antropólogos ou filósofos, não somos heróis do pensamento, somos produtos do nosso tempo. Se esse tipo de debate feito por Bruno Latour e, no Brasil, por Eduardo Viveiros de Castro é possível, é precisamente porque as condiçóes históricas hoje são tais, que esse paradigma dá sinais de desgaste.

Jean-François Véran: Então, se entendi bem, em nenhum momento você colocou em causa a legitimidade da ciência, da biologia, da física em produzir leis que são universais. $\mathrm{O}$ que você coloca em causa é o corte epistemológico entre ciências da natureza e ciências da cultura. Então, hoje, ao que parece, o que foi dito segue no sentido de afirmar que a genética, as neurociências, as ciências cognitivas e mesmo a etologia, cada vez mais, se interessam pelos objetos que antes eram essencialmente os da antropologia. Penso na maneira como a genética trabalha o conceito de identidade, na maneira como as neurociências trabalham o conceito de cultura, e vemos que há uma penetração — que se pode, sem dúvida alguma, saudar - dos objetos ontem consagrados da antropologia nas ciências naturais. Como por vezes se pensa, ao invés de se traduzir por uma extensão do naturalismo (que explica por leis naturais o que ontem se explicava pelo social e pela cultura), essas ciências, pelo contrário, demonstram o que você afirma desde sempre: a separaçáo impossível, ou a infertilidade da separação, em termos de natureza e de cultura. Penso nos trabalhos sobre a plasticidade cerebral em neurologia, nos quais se vê muito bem que não se pode pensar o cérebro sem a cultura, ou nos trabalhos sobre a epigenética que mostram que a noçáo de patrimônio não existe. Temos aí, portanto, o campo desse encontro epistemológico a que você convida. Contudo, se os fundamentos epistemológicos das ciências naturais estão cada vez mais consolidados, tenho a impressão de que a antropologia, por sua vez, parece cada vez mais aplicar a si própria o relativismo que ela aplicava, com a antropologia cultural, a esses antigos nativos. Refiro-me principalmente à corrente interpretativista, desde Geertz e outros, que faz com que tenhamos não apenas um hiato na aproximação entre os objetos, mas também um afastamento das bases epistemológicas - considerando que, aqui mesmo, nesta universidade, tenho muita dificuldade com estudantes de antropologia que se perderam um pouco no relativismo, para os quais não existe absolutamente nenhuma forma de positividade possível 
em ciências sociais. Assim, no momento mesmo em que a aproximação dos objetos se opera, tem-se um desgaste das condiçóes epistemológicas das ciências sociais. Como responder a esses estudantes?

Philippe Descola: Li recentemente o último livro do meu amigo Maurice Bloch, um defensor da transposição de algumas conquistas das ciências cognitivas para a antropologia e que ataca com virulência a antropologia interpretativa, em Anthropology and the cognitive challenge [Antropologia e o desafio cognitivo]. ${ }^{6}$ Mas me incomodou um pouco o fato de ele construir uma espécie de "homem de palha", como se diz em inglês, para encarnar a antropologia interpretativa, e que dá toda a impressão de ser a figura de Geertz (embora não me lembre de ter sido citado explicitamente). Porém, por mais importante que seja, Geertz morreu já faz alguns anos. E o que é essa antropologia interpretativa, essa antropologia hermenêutica? De fato, é uma tendência de uma parte da antropologia norte-americana. Sem dúvida, é a mais presente no Brasil e, aliás, talvez entre os sociólogos. É uma abordagem culturalista simplificada, que transpôs para os Estados Unidos os fundamentos da abordagem hermenêutica alemá da segunda metade do século XIX. Para mim, é algo que pertence a uma história antiga do pensamento, da filosofia, das ciências sociais (que sequer leva em consideração personalidades consideráveis dessa corrente, como o neokantiano Ernst Cassirer, por exemplo) e que, de certo modo, murmura - peço desculpas por falar tão francamente, mas penso que é esta a finalidade do exercício para o qual fui convidado - numa produção etnográfica de maior ou de menor qualidade, que é tida por antropologia. Ora, a etnografia, mesmo escrita de maneira agradável, não é antropologia. A etnografia é efetivamente uma descrição indutiva de realidades sociais para as quais o método hermenêutico pode, algumas vezes, constituir uma ferramenta interessante. Mas isso não permite repensar os conceitos por meio dos quais tentamos compreender o mundo e agir sobre ele. E, se a antropologia pode servir para alguma coisa, é nesse âmbito: trata-se de um projeto que é também intelectual, mas é um projeto político, um projeto de transformação das condições nas quais encaramos a vida comum. Para falar francamente, a fecundidade revolucionária do marxismo-leninismo, em minha opiniāo, se esgotou, e é urgente pensar outras formas de viver juntos - sem que seja necessariamente um "viver juntos" harmonioso, já que as relaçôes de força não desaparecem -, conceitualizadas de uma maneira diferente daquela que havia sido a norma no século XIX. Então, se nós podemos contribuir — quando digo "nós", refiro-me às ciências sociais - com alguma coisa, é precisamente aí. E não vejo, realmente, de que forma uma antropologia do tipo geertziana poderia contribuir para um projeto desse tipo, quaisquer que sejam, aliás, as qualidades eminentes de Geertz, grande estilista, analista sutil e irônico e etnógrafo rigoroso. No fundo, tudo depende dos interlocutores que

\footnotetext{
${ }^{6} \mathrm{BLOCH}$, Maurice. Anthropology and the cognitive challenge. New departures in anthropology. Cambridge: Cambridge University Press, 2012.
} 
estabelecemos. Em minha opinião, há interlocutores que devemos recusar por não haver fecundidade intelectual no diálogo. É verdade que, por um lado, é muito confortável fazer antropologia interpretativa. Eu poderia ter passado a minha vida inteira fazendo antropologia interpretativa dos Achuar, com Anne Christine Taylor. Ambos sabemos muito sobre essa sociedade, não somos idiotas, então poderíamos ter repisado a thick etnography [etnografia densa] e desenvolvido infinitamente interpretaçôes de tipo geertzianas. Em si mesmo, não é algo completamente negligenciável - é, aliás, um gênero que eu mesmo pratiquei um pouco, em meu livro Les lances du crépuscule [As lanças do crepúsculo] $]^{7}$, e foi assim que ele foi recebido nos Estados Unidos. Mas trata-se de um tipo de operação intelectual completamente diferente da antropologia tal como a concebo. Desse ponto de vista, penso que há um efeito de perspectiva ou de foco: em meio a milhares de antropólogos que trabalham nos Estados Unidos, temos tendência a ver somente o pântano majoritário da antropologia interpretativa, ao passo que outros, minoritários, mas muito férteis, não são visíveis nesse oceano; entretanto, eles existem e é com eles que muitos de nós, na Europa, estabelecemos um diálogo: Sahlins, Wagner, Das, Robbins, e muitos outros.

Carlos Fausto: Gostaria de fazer três perguntas sobre a construção do seu projeto intelectual mais recente. A primeira pergunta diz respeito a uma categoria fundamental, desde o início, que é a categoria de "não humano". Essa categoria é subdeterminada no seu trabalho, é uma espécie de "mot valise". Eu gostaria que você falasse sobre a importância dessa categoria no seu trabalho, que, se não me engano, aparece desde La nature domestique. A segunda questão diz respeito à diferença entre duas categorias, digamos, mais intelectuais, dois conceitos: um deles, que é fundamental em La nature domestique e desaparece no seu trabalho posterior, é a categoria de "prática social". Talvez ela seja mais importante justamente em La nature domestique, e foi sendo substituída ao longo do seu trabalho pela categoria de "ontologia". Eu gostaria de saber se isso significa uma passagem da etnografia à antropologia, ou se corresponde a uma economia intelectual de outro tipo. Por fim, você se referiu a um "espírito do tempo". Eu gostaria de pensar esse espírito do tempo em relação a uma questáo interna à antropologia, portanto mais específica, que é o retorno da categoria de animismo (que aparece num artigo dos anos 90, de Bird-David). Gostaria de saber como você interpreta esse retorno do animismo e se, digamos, isso não é uma espécie de vingança de Lévy-Bruhl contra a razão classificatória de Lévi-Strauss.

Philippe Descola: Não estou muito satisfeito com essa noção de "não humano". Como você disse, é um mot valise, um termo "por falta". Ela permite inserir, num conjunto, coisas que antes tivemos uma tendência demasiadamente grande a diferenciar: plantas, animais, qualidades, divindades, teoremas, conceitos filosóficos etc. É isso: tudo o que pode viver

${ }^{7}$ DESCOLA, Philippe. As lanças do crepúsculo. São Paulo: Cosac \& Naify, 2006 [1993]. 
por dispositivos de qualificação autônomos, que são, evidentemente, em determinados casos, ativados por humanos de maneira relativamente dependente. Mas estou perfeitamente de acordo que se trata de uma noção completamente provisória, de que é preciso poder se desfazer. Mas, ao mesmo tempo, para poder pensar e fazer com que se compreenda o que é feito - e, em particular, o que faço — escolhi utilizar essa noção, como Latour havia feito também, por comodidade, de modo temporário, provisório, até que chegássemos a forjar conceitos que fossem mais pertinentes. Isso tem a vantagem de ter um lado militante, se me permitem dizê-lo, cujos resultados podem ser vistos neste livro editado por Sophie Houdart e Olivier Thiéry, que se chama Humains, non-humains: comment repeupler les sciencies sociales [Humanos, não humanos: como repovoar as ciências sociais]. ${ }^{8}$ É um livro bastante latouriano, uma coleção de estudos empíricos, nos quais os não humanos são tratados como agentes sociais. O que é um pouco complicado nesse livro é que os dois organizadores pediram a dinossauros, como Latour e eu, e a Elisabeth Claverie, Antoine Hennion e outros, que fizessem introduçôes para cada conjunto de artigos que mobilizam os não humanos, num âmbito particular. A teoria, a reflexividade, digamos, vêm dessas introduçóes. E as participaçôes de cada um dos autores - que são, em geral, bem jovens - consistem em estudos de caso muito descritivos, fenomenológicos, no sentido amplo. Assim, pode-se ver o que é produzido como efeito. É um livro muito interessante desse ponto de vista, ou seja, de se interrogar como, de fato, tratar cadeiras de rodas de pessoas deficientes, robôs, garrafas de água mineral, eletrodomésticos, vírus como atores sociais, ao invés de ter sempre os mesmos dispositivos, segundo os quais são tidos por artefatos ou por organismos ativados. Há, portanto, esse lado militante - e, aliás, a sociologia das ciências tradicional recebeu muito mal esse livro - , mas estamos numa fase de transição, isso é certo. É o que tenho a dizer sobre os não humanos, o que não é muito satisfatório.

No que concerne à prática social, esta é de fato uma questão interessante. Há pouco, precisei as condiçóes em que parti para o trabalho de campo quando escrevi La nature domestique. Eu queria reintroduzir a interatividade entre humanos e não humanos, ou seja, recusar todo sistema de determinação ecológica que ativasse instituiçôes, como no caso do materialismo ecológico, e os dispositivos de detecção de propriedade que permitissem construir sistemas simbólicos ou semióticos, à maneira de Lévi-Strauss. No entanto, queria, essencialmente, compreender a prática social. Para isso, a herança marxista era, sem dúvida, importante: a noção de práxis desempenhava um papel central (utilizei o conceito no título). Em Lévi-Strauss é igualmente importante. Há esse texto famoso, em La pensée sauvage [ $O$ pensamento selvagem]," em que Lévi-Strauss diz que concorda com Sartre que a práxis é "a totalidade fundamental" para as ciências humanas. Isso também me parecia central, mas o

\footnotetext{
${ }^{8}$ HOUDART, Sophie; THIERY, Olivier (Org.). Humains, non-humains. Comment repeupler les sciences sociales. Paris: La Découverte, 2011.

${ }^{9}$ LÉVI-STRAUSS, Claude. O pensamento selvagem. Campinas, São Paulo: Papirus, 1989 [1962].
} 
que fazer com essa noção de práxis? O que diz Lévi-Strauss quando se refere à práxis? Ele diz que entre práticas e práxis há sempre um esquema mediador que permite a uma matéria e a uma forma se realizarem como estrutura. Seguindo essa ideia, fui levado a ir além da simples descrição da prática social, que eu já havia começado a esquematizar em La nature domestique, uma vez que havia dois esquemas principais de interação ligados às duas formas do sistema dravidiano: a relação com os consanguíneos e a relação com os afins. E fui um pouco mais longe ainda, ao me perguntar de onde esses esquemas se originaram. Seria possível considerar, por exemplo, que são fruto da contingência, o que é, grosso modo, a posiçáo do interacionismo; ou da imitação repetida, porém caso a caso, em situaçôes idênticas. Mas, devido à minha inclinação estruturalista, isso me parecia difícil de admitir. E, além disso, de certo modo, isso me parecia fugir à dificuldade: no fim das contas, é possível descrever processos, mas a maneira como esses processos vão se estabilizar em sistemas de interação escapa mais ou menos à descrição etnográfica, que atua, antes de tudo, sobre o acontecimento. E foi por isso que busquei disposiçôes que precedessem a prática social cotidiana, que chamei de "esquemas" em referência a uma filiação que vai de Kant a Lévi-Strauss, passando pela psicologia do desenvolvimento. Talvez eu tenha levado essa hipótese muito longe, ao partir do princípio de que, no ponto de partida, estão essas identificaçóes ontológicas: o que é central é esse sujeito que conhece, que interage com seu meio ambiente, e que, devido ao que percebe e ativa nele, se inscreverá no interior de um desses esquemas de identificação e o estabilizará. É dessa maneira que vejo agora a prática social, de uma maneira mais estrutural do que na época em que escrevi La nature domestique, mas em que a noção de esquema já existia em filigrana.

Quanto à última questão, sobre o animismo e o espírito do tempo, empreguei a palavra "animismo" pela primeira vez em 1990, numa comunicação apresentada no colóquio da $E u-$ ropean Association of Social Anthropologists, publicada dois anos mais tarde com o título Societies of nature and the nature of society [Sociedades da natureza e a natureza da sociedade], ${ }^{10}$ ou seja, bem antes de Bird-David publicar seu artigo de 1999 sobre "o animismo revisitado" em Current Anthropology. ${ }^{11}$ Portanto, utilizei a noção motu proprio, numa época em que o termo havia caído em desuso. Talvez isso se deva ao fato de que eu havia lido Lévy-Bruhl (também bastante esquecido naquela época), bem antes de ler Tylor. Isso se deve também a um aspecto um tanto galanteador em antropologia — de que, no fundo, gosto muito - que consiste em retomar conceitos que serão constantemente retrabalhados extensamente e, por vezes, intensamente, ao longo do tempo. Isso torna as coisas um tanto difíceis, pois é preciso dizer "o animismo segundo Tylor, ou Descola, ou Bird-David etc."; mas, ao mesmo tempo,

\footnotetext{
${ }^{10}$ DESCOLA, Philippe. Societies of nature and the nature of society. In: KUPER, Adam (Org.). Conceptualizing society. Londres: Routledge, 1992.

${ }^{11}$ BIRD-DAVID, Nurit. 'Animism' revisited: personhood, environment and relational epistemology. Current Anthropology, Chicago: The University of Chicago Press, v. 40, n. S1, Special Issue "Culture. A second chance?", p. S67-S91, Feb. 1999.
} 
dá uma certa ideia de que há nessa ciência, ao longo do tempo, um verdadeiro progresso. Por que progresso? Faz alguns anos, um amigo me deu um pequeno livro sobre o animismo, publicado na Itália no meio do século XX. É um punhado de tolices, em que todo tipo de fatos disparatados estão misturados, e quando lemos coisas como essas, nos perguntamos: mas que história é essa de que não há progresso? Nas ciências sociais, sim: há fenômenos que são mais bem descritos e mais bem qualificados, mais bem problematizados em sua articulaçáo com outros fenômenos. E o que acho fascinante nesse empreendimento antropológico - como se vê em Tylor, Frazer, Lévy-Bruhl — é a vontade de mergulhar nesses dados tão enigmáticos, bizarros, mas que tenderam, durante muito tempo, a ser colocados num mesmo bloco. E, no fundo, uma das grandes contribuiçóes — há várias outras — que o estruturalismo nos trouxe foi fazer com que a maneira interessante de fazer ciência consistisse em modalizar sistemas de diferenças e, portanto, dissociar instituiçôes que durante muito tempo se tendeu a agregar. E continuamos a fazê-lo: em autores como Girard, na França, ou numa orientação completamente diferente, com a antropologia evolucionária, há essa tendência em explicar tudo por meio de uma espécie de chave fundamental, de arquétipo. Ora, pelo contrário, o que conta é chegar a dissociar, de modo a melhor reassociar, talvez, mais tarde. Portanto, essa noçáo de animismo objetiva, antes, dissociar. Em Par delà nature et culture discuto, por exemplo, o nahualismo. Quando se lê a literatura sobre o nahualismo, sobre o tonalismo no México, quando se retoma Frazer ou mesmo Tylor, entende-se que, efetivamente, naquela época, tudo isso estava misturado. Na realidade, quando se está atento aos dados, percebe-se que se trata de coisas muito diferentes. É isso que considero fascinante na antropologia. E é para isso também que serve a etnografia; ela só tem sentido como ciência das descriçóes precisas que permite esse trabalho de qualificação.

Nesse sentido, creio que foi de certo modo por acaso que a noção de "animismo" entrou tão em voga recentemente. Pessoas muito diversas se interessaram por ela sem terem, de forma alguma, a mesma concepção e por razóes muito distintas; algumas delas, como Graham Harvey, eram, além disso, grandes militantes de sua difusão. De repente, o animismo ressurgiu das cinzas. De minha parte, utilizei o termo porque, em relação ao totemismo classificatório, ele tinha a vantagem de enfatizar algo que havia sido completamente deixado de lado havia um bom tempo. As teorias do ritual não se interessavam por isso, na época; e não somente Lévi-Strauss, uma vez que, em Turner, por exemplo, a noção de animismo tampouco estava presente. É um pouco como a ideia de uma "antropologia da natureza”. Por vezes, isso pode enganar. Eu estava num colóquio em Berlim, há algumas semanas, em que Wendy James, que alguns de vocês conhecem, me disse que não se pode falar de "animismo". Ela trabalha com as populaçôes nilóticas do sul do Sudão, que são desqualificadas como "animistas" pelas populaçôes muçulmanas do Norte. E essas pessoas se refugiam em cavernas porque sâo bombardeadas. $\mathrm{Na}$ verdade, ela me censurava por contribuir para a difusão de um estereótipo estigmatizante, com consequências evidentemente dramáticas. Mas, é claro 
que o animismo dos Achuar definido pelos antropólogos, não é, de forma alguma, a mesma coisa que o animismo dos Dinka definido pelos missionários e o governo de Cartum!

CéSAR Gordon: A minha pergunta diz respeito ao modelo que você construiu, em que - apesar de todo o "espírito do tempo" que você esclareceu muito bem, de acordo com o seu percurso intelectual — há um traço bastante estruturalista, lévi-straussiano, na medida em que, para poder desenvolver essas "ontologias", esses grandes modos de identificação, foi preciso recorrer ao que você chama de "instrumentos conceituais" que são duas noçôes opostas: interioridade e fisicalidade. Elas me parecem um par estrutural mínimo, do qual, por meio da permutação e da combinação, é possível gerar quatro modelos diferentes. Eu acho que isso é muito bem-sucedido do ponto de vista da construçáo do modelo, mas a dúvida é em que medida, em que ponto, esse par mínimo se afasta do nosso dualismo natureza versus cultura, ou do dualismo mais antigo, cartesiano, no sentido da fisicalidade ou da natureza como domínio da matéria submetida às leis mecânicas do movimento; e da interioridade como domínio do espírito, da volição, da consciência e da liberdade (que equivale, de alguma maneira, à divisão cartesiana de onde emergem as nossas noçóes antropológicas, que parecem ultrapassadas, de natureza e cultura). Gostaria que você explicasse onde está a diferença desse par mínimo em relação aos conceitos maiores.

Philippe Descola: Gostaria de retomar, em primeiro lugar, o próprio dispositivo, antes de abordar as duas categorias. Eu vejo o dispositivo como um grupo de transformaçấo, no sentido lévi-straussiano, no sentido de um dos dois tipos dos quais Lévi-Strauss se utiliza em sua obra. Um deles é característico da morfologia goethiana, ou seja, o desenvolvimento a partir de um princípio originário, de um protótipo análogo à Urpflanze. A seguir, há outro tipo de grupo de transformação, inspirado por Arcy Thompson, e que Lévi-Strauss opera em Mythologiques [Mitológicas], ${ }^{12}$ que é uma transformação contínua: um tecido que se desfaz e se refaz em volta da terra redonda dos mitos. O primeiro é o das estruturas elementares do parentesco, ou seja, o princípio de reciprocidade que ele vê em ação entre os Bororo e que lhe parece ser o fundamento de toda a vida social, e que, em seguida, se complexifica em diferentes dispositivos que tornam possíveis todas as formas de casamento pelo desenvolvimento da transformação do princípio originário. Mas há, não obstante, um invariante que subsiste, que é a flexão da reciprocidade. É um tanto desse modo que vejo o uso que se pode fazer desse grupo de transformaçáo ontológica organizado em torno de um contraste entre fisicalidade e interioridade: trata-se de um modelo goethiano. A princípio, as duas noçôes têm um elemento de universalidade — creio, mas posso estar enganado. Retomo o que dizia

\footnotetext{
${ }^{12}$ LÉVI-STRAUSS, Claude. O cru e o cozido. Mitológicas I. São Paulo: Cosac Naify, 2004 [1964]; Do mel às cinzas. Mitológicas II. São Paulo: Cosac Naify, 2005 [1966]; A origem dos modos à mesa. Mitológicas III. São Paulo: Cosac Naify, 2006 [1968]; O homem nu. Mitológicas IV. São Paulo: Cosac Naify, 2011 [1971].
} 
há pouco, sobre a obsessão com os fundamentos: pareceu-me que o fundamento mais simples era, no fundo, o mais eficaz. Acredito realmente que o famoso dualismo cartesiano não é algo especificamente europeu e que se trata de algo bem mais complicado do que parece. Aliás, se lermos atentamente as Méditations métaphysiques [Meditaçôes metafísicas], veremos que não se trata de um dualismo simplista. De todo modo, digamos que o famoso dualismo cartesiano é uma variante entre outras dessas tensóes entre os dois planos que denomino "interioridade" e "fisicalidade". Assim, não se trata de um dualismo substancial, nem de um dualismo constituído, mas de um dualismo constituinte: é a capacidade que um indivíduo tem, baseado em suas próprias disposiçóes - as qualidades que ele se atribui do ponto de vista da fisicalidade e da interioridade —, de detectar continuidades ou descontinuidades entre si mesmo e os elementos do mundo. É possível que eu esteja completamente enganado sobre esses fundamentos - o que não teria grande importância, neste caso, no sentido do resultado produzido que continua sendo interessante, e é isso que importa. Quer dizer, podemos suprimir não somente o arcabouço da economia da descoberta, que mencionei brevemente para começar, mas até mesmo uma parte do arcabouço da economia da exposição, se os resultados produzidos forem pertinentes. Para retomar a metáfora do mecanismo experimental, da ferramenta de detecção que um físico pode empregar, pode-se considerar que, por mais que essa ferramenta de detecçáo possa estar mal calibrada, os resultados que ela fornece são interessantes. É assim que vejo. Nesse sentido, uma vez que os resultados alcançados são pertinentes - e creio que são —, não estou disposto a me engajar num debate filosófico sobre essa questão. Pertinentes no sentido de que isso permite, dito mais uma vez, compreender sistemas de diferenças e, através do estabelecimento desses grupos de transformação, compreender por que certas coisas se combinam ou não.

Andrea Daher: Falemos de sua experiência como curador da exposição La fabrique des images [A fábrica das imagens] no Musée du quai Branly, em 2011. Aproveitando seu último comentário sobre o maior interesse dos resultados pertinentes do que das ferramentas de detecção, gostaria de lhe fazer a seguinte pergunta: de que maneira essa exposição, do modo como ela foi concebida, pôde permitir ao público escapar de uma abordagem puramente formal das imagens, que resulta, entre outras coisas, de uma espécie de razão patrimonial ou museológica que é totalmente a nossa?

Philippe Descola: Fiz essa exposição como uma espécie de experiência sobre uma experiência. Quer dizer, comecei a trabalhar com as imagens como uma experiência, para ver se, no campo muito particular da figuraçáo, as proposiçóes que eu havia feito, lançando mão essencialmente de sistemas discursivos, eram sustentáveis. E, então, passei de um regime para o outro. A figuração era uma experiência de deslocamento e a exposição era uma experiência dentro da experiência. Tratava-se de ver se eu era capaz de fazer um público 
leigo perceber a pertinência das distinçôes que eu propunha nas imagens. Era uma exposição bastante coativa: passava-se por um vestíbulo em que se anunciava "aqui está o guia de leitura". Isso irritou algumas pessoas, sobretudo historiadores da arte. Mas se você admitisse o ponto de partida que eu propunha - observar as imagens —, você poderia ver se esses contrastes lhe pareceriam pertinentes. Há várias maneiras de verificar se isso funciona: a primeira é fazer públicos muito diferentes visitar a exposição - o que fiz muitas vezes - e, em seguida, olhar o livro de visitas em que as pessoas escrevem comentários, na saída da exposiçáo. Acredito que tenha sido eficaz no seguinte sentido: um comentário geral que me chegou foi que a exposição permitia ver, compreender ou constituir um guia de leitura ou de visão de outros objetos do museu. Isso é interessante porque o Musée du quai Branly é, no fundo, como todos os grandes museus de antropologia do mundo (com exceção do Pitt Rivers Museum de Oxford, a única que conheço), baseado numa divisão em áreas culturais, ou seja, baseado na ideia de que há afinidades entre os objetos pelo fato de eles terem sido produzidos numa mesma região, por uma mesma cultura ou numa mesma época, ou em transição uns em relação aos outros, no quadro de uma história da arte europeia. Mas, se for adotado um princípio completamente diferente, é possível propor às pessoas uma maneira de ver as imagens que não seja fundada nessa divisão em áreas culturais e em períodos estilísticos. E isso agradou, claramente, muita gente. Quer dizer que isso lhes permitiu escapar, além do mais, de uma determinada forma de ignorância, porque, embora familiar para nós, antropólogos, a divisão em áreas culturais é um pouco estranha para a maioria das pessoas. É preciso conhecê-las bem para chegar a compreender o simbolismo e a função das imagens numa região do mundo e numa determinada época. É nesse sentido que a exposição foi uma experiência, e as consequências foram várias. A que mais me tocou, ainda em relação ao livro de visitas, foi uma menininha que escreveu, no final: "Quando eu crescer, vou ser animista”. Exatamente: não se tratava, de forma alguma, das crianças e dos selvagens! Com trabalho, com um esforço considerável, conseguimos sair das evidências do naturalismo. É preciso reconhecer que o Musée du quai Branly permitiu esse tipo de experiência, que é muito rara. Quis também eliminar completamente qualquer ideia evolutiva, o que creio ser muito importante. Foi por isso que o início da sessão sobre o naturalismo coexistia com o fim da sessão sobre o animismo. Assim, máscaras wauja e as primeiras iluminuras de Fouquet estavam situadas no mesmo espaço. Depois do naturalismo, passava-se à Austrália, tipicamente considerado o mais primitivo dos continentes. Assim, qualquer ideia de evolução era dinamitada nessa apresentação, e foi exatamente isso o que quis fazer. A exposiçáo foi muito útil para que eu continuasse minhas reflexôes sobre as imagens (e sobre um aspecto importante delas). O que é uma imagem para mim? É um agente icônico. É um agente, no sentido clássico de uma entidade que exerce uma ação, mas que é icônico no sentido de que é uma coisa que figura qualidades de outra e que, por isso, pode às vezes se tornar essa outra coisa. E o dispositivo de apresentação que foi preciso inventar para essa exposição me 
permitiu avançar, por um lado, na compreensão conjunta dos mecanismos formais por meio dos quais as imagens são percebidas como agentes e, por outro lado, dos mecanismos da iconicidade, ou seja, dos conteúdos que as imagens figuram. Parece-me que os dois devem andar juntos, e foi o que tentei mostrar nessa exposição. Nada é fácil, porque uma exposição desse tipo, como qualquer trabalho sobre as imagens, é baseada no trabalho de historiadores e de etnólogos que estudaram as imagens neste ou naquele contexto cultural, o estatuto que elas têm, o uso que delas se faz etc. E, por vezes, é difícil fazer compreender que coisas que se assemelham em aparência - por exemplo, máscaras animais alasquianas e andinas, ou uma paisagem holandesa e uma paisagem chinesa - na realidade não se juntam e são de naturezas extremamente diferentes. É o limite que enfrentamos quando nos interessamos pelas imagens: o fato de que os dispositivos formais empregados para produzir imagens existem, afinal, em número relativamente limitado, e que alguns dentre eles podem servir a diferentes funçôes. Refletindo sobre a organização dessa exposição, tive a possibilidade de tomar consciência disso de uma maneira muito melhor do que se eu tivesse de escrever um texto, do que se tivesse sido simplesmente uma economia discursiva.

Els LAGRou: Eu queria saber o que você pensa da volta do interesse pelas imagens na antropologia, em geral, e na etnologia, em particular. Como isso ocorre? E como seu interesse pelas imagens se insere nesse movimento? Acho fascinante a maneira como você passa da ontologia à figuração. Eu gostaria de saber se isso foi premeditado ou se foi uma coincidência, pelo fato de que você teve a oportunidade de testar essa tradução de conceito em imagem para um grande público através da exposição, para depois desenvolvê-lo em detalhe (visto que a exposição foi acompanhada de vários debates e seminários). Acho também que é um procedimento muito interessante porque seria possível trabalhar de outra maneira. E a segunda questão é mais etnográfica. Sabemos que as ontologias supôem uma relação diferente com o meio ambiente. E isso tem consequências no estilo de figuração utilizado. Gostaria de saber como, nesse contexto de transformação, você situa a Amazônia. Você acha que poderia existir um animismo amazônico específico, que pode se traduzir em escolhas estilísticas e formais específicas? Gostaria de saber também se você pensa que poderíamos considerar o animismo amazônico como perspectivista ou não. Ou se você considera o perspectivismo como um exemplo mais específico que náo pode dar conta dessa região de um modo global.

Philippe Descola: Há, neste momento, entre os antropólogos, um fenômeno geral de interesse pelas imagens cujas razôes exatas eu não saberia apontar. Ele é extremamente impressionante entre os jovens pesquisadores e também entre pesquisadores mais experientes que, modificando suas áreas de interesse, se voltaram atualmente para essa questão. $\mathrm{Na}$ França, isso se liga em parte, talvez, ao dinamismo do Musée du quai Branly. Mas há todo um conjunto de fatores que devem ser considerados, sobretudo o fato de que tradiçôes teóri- 
cas muito diferentes podem convergir para um mesmo objeto, que se torna, então, "quente". Confesso que, no meu caso, se tratava, de saída, de algo um tanto instrumental. Eu havia evidenciado alguns campos da vida social em que contrastes ontológicos eram visíveis, partindo unicamente de documentos discursivos. Escolhi me voltar, em seguida, para as imagens por um interesse antigo pela história da arte e pela pintura, mas também porque eu me havia dito que, se esses contrastes ontológicos "funcionassem" para as imagens, isso significaria uma boa confirmação. Aliás, outro âmbito da vida social que também havia atraído o meu interesse era a espacializaçáo, os dispositivos de ordenação do espaço, que é também um âmbito relacionado à imagem. Ou ainda, o da temporalidade ou da duração, a ordenação da duração. Havia, naquele momento, esses três âmbitos que me interessavam. E decidi, afinal, me dedicar às imagens. Isso é efeito, sem dúvida nenhuma, de uma obrigação infernal, tanto na École des Hautes Études en Sciences Sociales quanto no Collège de France - cuja experiência vivo há muito tempo - , que consiste em oferecer, a cada ano, um curso sobre um tema diferente. No caso, se tratava de abordar um campo completamente novo, então pensei: por que não as imagens? Assim, saltei para o desconhecido e tomei as imagens por objeto.

O trabalho sobre a exposição e o trabalho sobre as imagens estiveram estreitamente ligados. Tive a sorte de poder me beneficiar de uma licença sabática de um ano, que passei em Munique, onde há tanto um célebre instituto de história da arte quanto um museu de etnologia com uma excelente biblioteca. Assim, me enterrei em Munique, uma cidade muito charmosa, mas onde as tentações de escapar ao trabalho são poucas. Então, trabalhei muito e constituí a biblioteca mental de imagens que os historiadores da arte adquirem muito cedo em sua formação e de que um antropólogo como eu não dispóe. Foi assim que trabalhei, associando aquilo que encontrei à tentativa de ver quais tipos de imagens podiam corresponder melhor ao que eu desejava mostrar. E avancei na busca para responder questóes muito concretas sobre as imagens: onde estão conservadas? O que se escreveu sobre elas? Como podemos fazer empréstimos para uma exposição?

No que diz respeito às imagens amazônicas, você levanta um ponto extremamente delicado. É que, para levar adiante o trabalho que comecei, seria preciso fazer uma coisa que não tenho coragem de fazer e que consiste em se dedicar àquilo que se pode chamar "estilos". Não no sentido da história da arte, mas no da morfologização das imagens, digamos. E se trata de interrogar as razóes pelas quais os estilos se desenvolvem, independentemente do que podemos saber, evidentemente, a respeito de questôes de transmissão, de influência e de difusão regional, e deixando de lado a ideia de arquétipos estilísticos universais. Não que essa última pista não possa ser profícua; alguns a levaram bem longe, como Carl Schuster, especialista em simbolismo iconográfico, que passou a vida inteira documentando os motivos no mundo inteiro, a fim de tentar encontrar famílias de motivos universais. Minha orientaçáo neoestruturalista, digamos assim, me afasta desse tipo de empreendimento. Mas o que seria muito interessante fazer, no caso, seria compreender por que no âmbito do animismo há, 
de fato, diferentes estilos. A iconicidade desempenhou um papel importante na Amazônia durante o período pré-histórico, mas não sabemos nada sobre essas imagens. Em contrapartida, as imagens amazônicas contemporâneas são pouco miméticas, enquanto no animismo circumboreal se atribui uma grande importância à iconicidade (a uma determinada forma de iconicidade, em todo caso). Por que a iconicidade desempenha um papel menor no mundo amazônico? Será porque as imagens são perspectivistas? Creio que não, uma vez que há formas de perspectivismo em outros lugares. Há casos exemplares, ou em todo caso muito bem documentados, na Sibéria (e isso desde Bogoras), onde há, entretanto, uma tradição estilística bastante diferente daquela da Amazônia. Não tenho respostas prontas, mas é um problema fundamental. Acredito que não se possa ir um pouco mais adiante nessa direção sem fazer esse trabalho de análise estilística. Há uma pista possível que não explorei (e não sei se o farei), em Par-delà nature et culture: há modos de identificação, formas ontológicas elementares, mas há também modos de relação. E a certas ontologias podem corresponder vários modos de relação. É possível que eles tenham um papel a desempenhar na definição desses estilos. Aí também o trabalho é enorme. No fundo, o que faço é propor; se as pessoas tomarem essas proposiçóes para tentar pô-las à prova com material etnográfico, será muito bom, mas é claro que se trata de um tipo de trabalho que eu mesmo náo poderia fazer. Isso é quase tudo do que posso dar como resposta. Mas é verdade que o animismo apresenta essa característica nas imagens, em relação a outros modos de identificação. Há uma variedade enorme, um panorama enorme, de certo modo, de formas de figuraçấo que chamam a atenção. Ao mesmo tempo, há elementos recorrentes que considero extremamente interessantes e que são muito reconfortantes, pois demonstram uma continuidade animista em regiôes do mundo muito afastadas umas das outras. Por exemplo, a máscara ma’betisek (Malásia) de xamã, metade tigre, metade humano, que encontrei em Maurice Bloch, figura uma possível mudança de perspectiva: num perfil, há a dimensão tigre do espírito; do outro lado, há não a dimensão humana, mas a dimensão de interioridade desse tigre figurada por um perfil humano. E basta passar de um para outro, se deslocando alguns centímetros, para mudar de perspectiva. Enfim, para responder de maneira incompleta: a questáo dos estilos está ainda por ser explorada.

Nina Vincent: Quando visitei a exposição La fabrique des images, a primeira coisa que me veio à cabeça foi vê-la como uma experiência de uma "fabricação de imagens" sua. Gostaria de tentar entender como você passou por esse processo de figuração, de composição de uma exposição: em primeiro lugar, a partir da escolha dos objetos, especialmente no que diz respeito à questão do apelo estético (que é uma questáo polêmica para os museus etnográficos) e aos dispositivos visuais, cenográficos, que me parecem ser aquilo que proporciona esse "dar a ver" da teoria transformada em exposição; em segundo lugar, gostaria de saber como essa exposição afetou o seu pensamento, a sua teoria sobre os objetos, especialmente no que 
diz respeito à questão da "agência". Seria no sentido de uma transição entre essa ideia dos objetos como uma consequência ou uma ilustração das ontologias, ou dos objetos e imagens compondo a construção dessas ontologias?

Philippe Descola: Vou responder primeiramente à segunda parte da questáo. Fazer a exposição desempenhou um papel importante nesse sentido. Como eu disse, no início havia um lado de verificação experimental: se funcionasse com as imagens, seria uma confirmação do que eu havia explicitado anteriormente a partir dos sistemas discursivos. E depois, ao longo do tempo, percebi - algo que deveria saber, pois não sou um completo ignorante em história da arte — que as imagens têm um regime de existência relativamente autônomo (ainda que os historiadores da arte se sirvam bastante do contexto histórico e, sobretudo, discursivo para explicá-las). E que, em certos casos, em particular no caso do naturalismo, elas prefiguram transformaçôes ontológicas que os textos só deixam explícitas muito mais tarde. Parti da ideia, efetivamente, de características elementares de cada uma dessas ontologias. Indaguei-me, por exemplo: como isso funciona no naturalismo? A ideia da perspectiva era importante, mas percebi que, bem antes da utilização sistemática da perspectiva linear, os dois elementos característicos do naturalismo - o caráter distintivo da interioridade humana, de um lado, e a obsessão com a descrição verossímil do mundo, de outro — já estavam presentes, desde muito cedo. Percebi que alguma coisa havia ocorrido, num determinado momento, na cultura visual do Ocidente, que indicava uma maneira diferente de ver, portanto de detectar (que é sempre a mesma coisa) qualidades, relaçóes nos objetos do mundo. Foi, de fato, o trabalho com as imagens, e mais particularmente o trabalho da exposição, que permitiu que eu me desse conta disso.

Quanto ao caráter de agência dos objetos, ele estava presente aí, uma vez que se trata de agentes icônicos que têm autonomia. Como transmitir isso aos espectadores sem utilizar o discurso? Tive a sorte de ter um cenógrafo nessa exposição com quem discuti muito a respeito dessas questóes para tentar transmitir a mensagem. Havia algo nesse sentido, por exemplo, na parte sobre o animismo (não sei se aqueles que viram a exposição repararam nisso). No fundo, o que é o animismo? Precisamente, são presenças, são agências que podem se estabilizar na forma de imagem ou não. E para tornar isso perceptível, decidimos usar um fundo uniforme, cuja iluminação variava, no entanto, por meio de um dispositivo luminoso. Um programa de computador (muito complicado, aliás) modulava a intensidade da luz e deslocava os focos de maneira aleatória para que se tivesse a impressão de que algo acontecia, mas não se soubesse o quê. $\mathrm{O}$ espectador não devia ter a impressão de uma variação sistemática; algo acontecia, havia uma presença, algo que se movimentava, mas não se sabia o quê. E, da mesma maneira, do ponto de vista sonoro, com o áudio-guia, era preciso também uma presença auditiva. Minhas leituras sobre as regióes circumboreais me fizeram pensar imediatamente que o mais adequado para isso era o barulho de passos na neve, de ruídos na bruma. No caso das pinturas aborígenes - que outrora eram desenhos na areia, em objetos rituais ou no corpo - , para destacar sua indexicalidade, pedi que elas fossem colocadas no 
chão, deitadas, enquanto, tradicionalmente, são penduradas nas paredes como numa galeria de pintura, digamos, como quadros contemporâneos. Há pequenas coisas como essas que o Musée du quai Branly permite fazer, ainda que a latitude nas formas de exposição não seja imensa. Então, por que fiz essas escolhas? Porque, de certo modo, a primeira exposição que Anne Christine Taylor, Stéphane Breton, Viveiros de Castro, Michael Houseman e outros fizeram no Musée du quai Branly, e que se chamava "O que é um corpo?", era uma belíssima exposição, mas cuja cenografia era complexa e muito menos didática, pedagógica, que a minha. Assim, fiz uma etnografia da visita: fiquei plantado lá, depois observei como as pessoas visitavam essa exposição, e percebi que elas não compreendiam a proposta porque não iam aos lugares corretos, não paravam no início para compreender as explicaçôes dadas etc. $\mathrm{E}$ tirei consequências disso, impondo um percurso em La fabrique des images. Como disse, esta exposição era muito didática, com um vestíbulo em que se dizia: "eis o que tem de ser visto". E creio que o resultado tenha sido positivo, quer dizer, que muitas pessoas ficaram satisfeitas com o fato de sermos didáticos. Mais uma vez, para retomar o que dizia sobre os museus de etnologia, a partir do momento em que saímos do sistema das áreas culturais, há duas possibilidades: ou se consideram temáticas gerais, uma classe de objetos numa regiấo do mundo, como os têxteis andinos ou os malanggan melanésios (e, no fundo, nesse caso, acabamos por não sair muito da disposição em áreas culturais); ou então tomamos um objeto particular que tem uma presença quase universal, que se declina em diferentes formas, como as máscaras, os escudos etc. Mas, se for o caso de desenvolver um argumento problematizado, não se pode fazer de outro modo, a não ser explicando de saída: "é isso que você vai ver". Posso causar arrepios ao dizer isso, mas acho que é preciso jogar o jogo até o fim.

Andrea Daher: Ou seja, como ela acaba de dizer, é a sua fábrica...

Philippe Descola: O antropólogo, no fundo, é isso: a fábrica é sempre ele próprio. No trabalho de campo, isso é evidente; a etnografia é isso. $\mathrm{O}$ ateliê do etnógrafo é ele próprio, as relaçôes que ele estabelece com as pessoas. Pode-se considerar que, a seguir, também, a fábrica é o próprio antropólogo, na série de experimentações que nascem dessa situação inicial.

Andrea Daher: Para encerrar esta entrevista, eu lhe perguntaria de que maneira seu trabalho mais recente, sobre as abordagens antropológicas da paisagem, vem se integrar à sua proposta de uma antropologia da natureza, mais precisamente após essas reflexôes sobre os modos de figuração ontológicos.

Philippe Descola: Na verdade, me interesso pela paisagem há muito tempo. Dei seminários sobre esse tema durante dois anos consecutivos, na École des Hautes Études en Sciences Sociales, porque a paisagem é um objeto antropológico fascinante. Em primeiro lugar porque 
ela se situa na junção entre um dispositivo perceptivo e um dispositivo cultural. Segundo a teoria clássica das paisagens, aprendemos a observar uma paisagem in vivo porque já vimos paisagens pintadas. Gombrich foi o primeiro, sem dúvida, a sistematizar a teoria das paisagens nessa forma argumentativa. Mas se trata, não obstante, de uma ideia antiga, que encontramos em filigrana já em Burckhardt. $\mathrm{Na}$ verdade, é a conjunção entre os dois, ou seja, um olhar voltado para um meio ambiente informado por um esquema visual que é um traço mnemésico dos quadros que contemplamos.

Segundo problema antropológico interessante: a paisagem no sentido da figuração mimética de um pedaço de meio ambiente. Tradicionalmente, dizemos que isso só existe de forma sistemática no Extremo Oriente e, a seguir, na Europa a partir do Renascimento, com todos os tipos de controvérsias que dizem respeito às pinturas de paisagem, aos afrescos de paisagens romanas e, até mesmo, gregas. Toda a questão que se coloca aqui é saber se essa noção de paisagem pode ser estendida para além da era histórica em que as figuraçôes miméticas de paisagem foram produzidas. Para isso há duas respostas possíveis, que não considero, nem uma, nem outra, satisfatórias. A primeira consiste em dizer: é paisagem toda apreensão subjetiva dos lugares. É a posição característica de uma parte da antropologia anglo-americana, e também de uma parte de um ramo fenomenológico da antropologia e da arqueologia, como a de Christopher Tilly. Ela náo me parece muito interessante porque em qualquer lugar, de fato, se tem uma apreensão subjetiva do espaço. E decidir chamar isso de "paisagem" não nos traz muita coisa. A segunda abordagem é oriunda do que poderíamos chamar de escola francesa da paisagem. Penso, em particular, em Augustin Berque, um geógrafo cultural, e em Alain Roger, um filósofo especialista em estética, que enfatizaram a necessidade de não falar de paisagem a não ser se houver critérios sobre os quais se possa ter consenso. O mais restritivo deles é Augustin Berque, para quem existem quatro critérios: a existência de um termo, de representaçóes literárias, de representaçóes picturais e de artializaçâo in situ (termo já empregado por Alain Roger), ou seja, a existência de jardins como modelos reduzidos de paisagens. Isso é admissível, mas evidentemente significará que a investigação sobre a paisagem onde nenhum desses critérios possa ser encontrado estará imediatamente suspensa. Então, a posição que tento defender é a de uma via intermediária entre essas duas definiçóes - uma excessivamente "extensionista" e outra excessivamente "intensionista" - que consiste em dizer que uma paisagem é um pedaço de meio ambiente transformado num signo de outra coisa que ele mesmo. Ele pode ser uma figuração, ou ainda um pedaço de meio ambiente transformado (como um jardim). Chamo isso "transfiguração", tomando essa palavra no sentido da fgura, segundo Erich Auerbach, ou seja, algo que está a meio caminho entre uma imagem e uma forma, algo que evidencia um esquema produtivo. Estou bem no início, mas procuro ver como esses processos de transfiguração existem em outros lugares diferentes das civilizaçôes em que uma pintura figurativa das imagens ou uma tradiçẫo dos jardins se desenvolveram. Dou um exemplo: há uma literatura 
pouco utilizada sobre os jardins de subsistência, que são lugares em que se cultivam víveres e, ao mesmo tempo, muitas outras coisas (modelos reduzidos do cosmos, imagens do corpo fragmentado de um ancestral, miniaturas da floresta etc.). Essa literatura existe para a Melanésia, e é bem conhecida depois de Coral gardens, de Malinovski. ${ }^{13}$ Há, ainda, uma belíssima etnografia sobre o Vanuatu, e material para a Amazônia e para a Ásia do Sudeste. O jardim medieval também é isso: em primeiro lugar, um jardim de plantas condimentícias e medicinais e um jardim de legumes, que tem uma funçáo nutritiva. Mas, ao mesmo tempo, é um lugar que tem um simbolismo extremamente complexo e que vale por algo diferente do que é. Assim, a perspectiva que desenvolvo é esta, interessado, num primeiro momento, nos dispositivos de transfiguração in situ. Alain Roger propôs uma distinção útil entre o que ele chama a "artialização in visu" e a "artialização in situ". A primeira consiste em pintar os meios ambientes, transformando-os, já que se trata de um trabalho de figuração mimética. A segunda consiste em transformar localmente um meio ambiente, na forma, por exemplo, do paisagismo clássico dos jardins chineses ou do landscape gardening, em sua grande tradição, na Inglaterra do século XVIII. Ora, penso que a transfiguração in situ não se aplica somente aos jardins de lazer, mas está presente também em certos jardins de subsistência — e é o que vou estudar neste ano letivo, no meu curso do Collège de France. Então, a outra pista interessante é a miniaturização, porque, no fundo, uma paisagem, in visu ou in situ, é sempre um modelo reduzido de alguma coisa. Vocês se lembram, sem dúvida, do belo texto de Lévi-Strauss sobre o colarinho de rendas de Clouet, em que diz que o que a pintura ou a arte fazem ao mudar a escala é conferir a capacidade de ver o conjunto de maneiras possíveis de realizar o objeto que se tem diante dos olhos. Em outras palavras, a arte, de certo modo, é uma experiência estrutural do conjunto de maneiras possíveis de dar conta de um protótipo realizado de uma única maneira, aquela que temos diante dos olhos, mas que podemos, nós mesmos, fazer variar, imaginando outras possibilidades. Contudo, essa característica da miniatura - a de fazer nascer a emoção estética, tanto de uma apreensão sintética das propriedades de um objeto quanto de uma analítica de suas condiçôes possíveis de realização — não explica completamente a redução de escala na figuração de paisagem. Neste caso, o interessante é que ela é um modelo reduzido, não somente de um objeto (um humano, um vaso de flores etc.), mas de um contexto de relaçôes possíveis, que nos é permitido vir a ocupar, e que dá essa impressão muito forte, ao observarmos certos quadros, de que poderíamos entrar neles e nos misturar à vida pintada.

São esses os dois campos em que busco explorar a noçáo de paisagem para que ela se torne antropologicamente produtiva, sem ser banalmente estendida a qualquer forma de apreensão subjetiva dos lugares.

\footnotetext{
${ }^{13}$ MALINOVSKI, Bronislaw. Coral gardens and their magic. A study of the methods of tilling the soil and of agricultural rites in the Trobriand Islands. Londres: Allen \& Unwin, 1935. 2 v.
} 